Bascoul, A.M., Tommelein, I.D., Tillmann, P., and Muxen, S. (2018). "Towards Facility Management Participation in Design: A UCSF Case Study." In: Proc. $26^{\text {th }}$ Annual Conference of the International. Group for Lean Construction (IGLC), González, V.A. (ed.), Chennai, India, pp. 505-515. DOI: doi.org/10.24928/2018/0209. Available at: www.iglc.net.

\title{
TOWARDS FACILITY MANAGEMENT PARTICIPATION IN DESIGN: A UCSF CASE STUDY
}

\author{
Audrey M. Bascoul ${ }^{1}$, Iris D. Tommelein ${ }^{2}$, Patricia Tillmann ${ }^{3}$, and Scott Muxen ${ }^{4}$
}

\begin{abstract}
The discipline of Facility Management (FM) emerged in the 1970s triggered by the concomitance of (1) increasing complexity in the workplace and (2) understanding of an interdependence between users' behaviors and building design. Despite the existence of FM, a number of buildings today still fail to deliver value during the occupation phase. Although various causes contribute to such failures, this paper focuses on the lack of strategic involvement of Facilities Managers (FMs) in design. It uses the University of California, San Francisco (UCSF) as a case study to describe how an organization has-in the course of its Lean journey-learned the importance, not only of considering FM requirements during design, but more importantly of actively engaging FMs early in the design process. Benefits experienced by UCSF are multiple. One is that FMs understand, perhaps better than designers, the complexity of the programs housed by UCSF buildings and the constraints this complexity imposes on the design requirements. This helps FMs advise on trade-offs between their preferences for simple (e.g., easy-to-maintain) systems and the programs' needs for complex systems.
\end{abstract}

\section{KEYWORDS}

Facility Management, Case Study, Design Management

\section{INTRODUCTION}

The discipline of FM emerged in the 1970s due to concomitance of (1) increasing complexity in the workplace and (2) the understanding of an interdependence between building users' behaviors and building design.

1 PhD, Civil and Envir. Engrg. Dept., Univ. of California, Berkeley, CA 94720-1712, USA, audrey.bascoul@berkeley.edu, Project Engineer, Dome Construction, orcid.org/0000-0001-8176-0041

2 Professor, Civil and Envir. Engrg. Dept., Director, Project Production Systems Lab., Univ. of California, Berkeley, CA 94720-1712, tommelein@berkeley.edu, orcid.org/0000-0002-9941-6596

3 Sr. Lean Manager, Real Estate Dept., Univ. of California, San Francisco, CA 94143, patricia.andretillmann@ucsf.edu, orcid.org/0000-0003-3420-3132

4 Assistant Vice Chancellor, Capital Planning Dept., Univ. of California, San Francisco, CA, scott.muxen@ucsf.edu 
Information telecommunication technology drastically changed how office work was organized in the 1970s. This shift in how information was distributed and shared, along with other technological breakthroughs, made the built environment more dynamic. As a result, customers became more vocal and what they valued became more varied. FM was created to operate and "steer" the building upon delivery by the Design and Construction (D\&C) team, so that it would continue to deliver customer value for many years.

The understanding that people are influenced by the environment in which they evolve dates back many years (e.g., Nightingale 1857) However it is not until the 1980s that the discipline of evidence-based design (EBD), which focuses on the relationship between buildings and user behaviors, was introduced by Ulrich (1984). FM was tasked with observing and managing the interdependence between the building and its users (the terms "occupants" and "users" are used interchangeably in this paper).

Despite the existence of FM ever since, buildings still fail to deliver value during the occupation phase. Although various causes contribute to building failures, this paper focuses on the lack of strategic FM involvement in project delivery, and specifically on FM involvement in design. It provides a case study to illustrate how such involvement may occur.

The paper is organized as follows. The first section lists definitions of FM encountered in the literature as well as the tasks FM encompasses. The intent is to show that (1) the discipline of FM encompasses many activities and (2) no consensus exists on how to do FM. The second section highlights similarities between the emergence of FM and the emergence of EBD. The intent is to invite the Lean community to explore FM with EBD eyes. The third section describes the UCSF case study. The intent is to encourage owners to reflect on how they integrate FM in design and the impact thereof on FM's satisfaction with the building's operability, maintainability, and adaptability to future needs once constructed. The fourth section presents the conclusions of this research.

\section{FM DEFINITIONS AND TASKS}

Various literature reviews on FM exist. Bascoul (2017) consolidated a list of 17 definitions of FM, based on literature reviews by Tay and Ooi (2001), Shohet and Lavy (2004), Noor and Pitt (2009), and Waheed and Fernie (2009). From these definitions, trying to determine what is actually managed by FM gives different answers, such as:

1. "Buildings, systems, equipment, furniture" (Becker 1990).

2. "The buildings and infrastructure" (Barrett and Baldry 2003).

3. "Buildings and accommodation, services and resources" (Regterschot 1990).

4. "Services and support infrastructure" (Atkin and Brooks 2015).

5. "Building assets as workplaces" (Varcoe 2000).

6. "Non-core company assets" (Nelson and Alexander 2002).

This paper adopts Atkin and Brooks' (2015) definition: "FM is creating an environment that is conducive to the organization's primary processes and activities, 
taking an integrated view of its services and support infrastructure, and using them to achieve end-user satisfaction and best value through support for, and enhancement of, the core business."

The authors chose this definition for the following reasons: (1) the importance put on FM for the success of the organization, (2) the consideration of both end-user and business (which are not the same, as Finch (2010) notes), and (3) the emphasis on bestvalue as opposed to cost effectiveness.

Regarding FM tasks, the scope of FM is so large and varies so much from one organization to another that it is hard to define (Chanter and Swallow 1996, Waheed and Fernie 2009). Unsurprisingly, Noor and Pitt (2009) write that "there is no universal approach to managing facilities." FM role has received many names:

1. "Hybrid manager," "business leader" (Alexander 1994).

2. "Teacher," "housekeeper," "manager," and "juggler" (Aune et al. 2009).

3. "Jack of all trades" (Tay and Ooi 2001).

4. "Innovation leader" (Noor and Pitt 2009), "user-technician" or "super-user" (Aune et al. 2009).

Overall, the literature review suggests that FM has traditionally been considered as a support department rather than a core department, that must be cost-efficiency driven, and that is not directly contributing to meeting the business objectives (Chanter and Swallow 1996, Grimshaw 2007, Noor and Pitt 2009). In this respect, Clayton et al. (1999) write: "Maintenance, remodeling, replacement of components and daily facility operations consume a large portion of the cost of doing business." More recent publications also show that FM is ready for a paradigm shift. This paradigm shift can only happen by acknowledging the value that "FM bring(s) towards organizational effectiveness" (Noor and Pitt 2009).

The next section links the emergence of FM to Florence Nightingale and EBD.

\section{EMERGENCE OF FM}

Although some FM literature reviews links the emergence of FM in the US to the creation of the Herman Miller Research Corporation, Finch (2010) links the origin of FM to Florence Nightingale.

While Nightingale is more frequently associated with nursing than FM, one cannot downplay her understanding of the relationship between the built environment and patient recovery. In her Notes on Nursing (1857), Nightingale makes four recommendations with regards to the built environment in order to accelerate patient recovery. Hospitals should have (1) outside air over recirculated air, (2) daylight over artificial lighting or dark rooms, (3) wall and floor finishes that are easy to clean, and (4) variety (in aesthetics) (Finch 2010).

Florence Nightingale's observations are a landmark in the EBD timeline (Rybkowski 2009). EBD is defined as "the conscientious and judicious use of current best evidence, and its critical interpretation, to make significant design decisions for each unique project. 
These design decisions should be based on sound hypotheses related to measurable outcomes" (Hamilton 2006). The discipline of EBD was formalized later, by Ulrich (1984).

Thus, FM and EBD have as a common characteristic that they both look at the interdependence between buildings and users. FMs' unique knowledge could play a key role to guide EBD efforts in project delivery. Participating in EBD is one of many ways to strategically involve FMs in project delivery. The next section explores additional opportunities.

\section{CASE FOR FM INTEGRATION}

This section captures arguments found in the literature on the value of integrating FM in the delivery of projects during programming, design, planning, and construction. Arguments in favor of FM involvement in the commissioning phase and the use phase are not captured in this paper, since they are abundantly covered in the literature.

\section{PROGRAMMING PHASE}

The early involvement of customer user groups (including FMs) has been acknowledged to be critical in the programming phase of construction projects. Because FM maintains buildings, it constitutes a user group that has specific needs as well. In addition to being a user group, FM has two areas of knowledge that can be valuable to the design and construction team.

First, FM knows building users (their behaviors, preference, processes, and activities), since FM interacts with them at the operational level. This is the reason why Aune et al. (2009) compare FM with "super-users" because they "see" the users.

Second, FM has knowledge about how buildings have been satisfying users' needs in the past. Thus, FM can be the "feedback loop" and present lessons learned on former projects to inform the project definition phase, thereby preventing architects and engineers from repeating errors (Aune et al. 2009) and driving them to further innovate.

\section{DESIGN PHASE}

Numerous studies have pointed out the importance of involving FM in design. Kalantari et al. (2017) list 13 such studies, and Bascoul (2017) adds 3 more: Mitropoulous and Howell (2002), Aune and Bye (2005), and McAuley et al. (2016). The next paragraphs summarize the arguments given in favor of FM involvement in the design phase.

A first argument is informing the design of maintenance considerations (Aune and Bye 2005) or "maintenance practicality" (Assaf et al. 1996) and thereby drive down building life cycle cost (Meng 2013). Accessibility of equipment, location and sizing of maintenance catwalks, selection of mechanical systems depending on their reliability, location and sizing of janitors' and storage spaces are examples of decisions made in the design phase that FM could inform.

A second argument is increasing building efficiency. Energy efficiency can increase if FM better understands the design intent before occupancy (Aune and Bye 2005) 
A third argument is avoiding negative design iteration. Mitropoulous and Howell (2002) investigated design iteration encountered on an office-space renovation project. Through interviews with project team members, they identified: the conditions that created design iteration, causes for design iteration, the effect of design iteration on design, and their effect on cost and time. They concluded that most of the design iteration was due to late discovery of existing conditions. Yet, awareness of existing conditions is part of FM's tacit knowledge, hence the value of integrating FMs in the design phase might have avoided some negative iteration.

A fourth argument is a better translation of customer needs (Meng 2013). This converges with the arguments in favor of FM involvement in the programming phase.

The value of FM involvement in design certainly goes even beyond these arguments, because FM "hold(s) tacit and experience-based knowledge" (Aune and Bye 2005). This makes FM specifically suited to reminding architects whether or not their performance expectations are reasonable, since "designers may sometimes expect their buildings to operate in ways that are not practically feasible" (Kalantari et al. 2017).

\section{PLANNING PHASE}

FM strategic involvement in the planning phase is critical for facility upgrades (Bascoul et al. 2017). FM knows how equipment and systems function. It possesses tacit knowledge about existing conditions that may or may not have been captured in as-builts (as it often happens in successive "small" upgrades). It also has accumulated knowledge about how systems are fine-tuned, and the extent to which systems are sensitive to perturbations. FM can inform the construction team about the feasibility and the risks associated with the construction means and methods proposed. FM may also be able to recommend strategies on how to tackle the job.

\section{CONSTRUCTION PHASE}

FM involvement in the construction phase is valuable (Enoma 2005, Aune and Bye 2005) and necessary because FM involvement in the programming- and design phases is insufficient to guarantee that what they specified in programming and design has been understood by the design and construction team and will not be altered. This notwithstanding, FM is often no longer consulted in the construction phase, although design changes still happen. Finishes are a case in point. FM have tacit knowledge about the maintainability of finishes and how the products used evolve and last with time. However, substitution with other products and manufacturers still happen during construction for various reasons, hence the necessity of keeping FM informed and involved during this phase.

The next section describes UCSF's Lean journey and how it started to integrate FM in project delivery increasingly early. 


\section{UCSF CASE STUDY}

Given that FM involves many tasks and UCSF operates many facilities, UCSF has different FM departments with different functions. This section only refers to FM that is responsible for maintaining buildings.

\section{UCSF'S LEAN JOURNEY}

UCSF has been using Lean for delivering projects since 2007 (Bade and Haas 2015) and has been successful at it on complex projects exceeding $\$ 2$ billion and many others.

When UCSF began developing Mission Bay in the late 1990s, it used design-bidbuild contracts and Construction Management (CM) at risk delivery methods. UCSF initiated its Lean journey by addressing the root cause of poor project performance: the misalignment between the operating system, the organization, and the commercial terms (contract). These three elements constitute the Lean Triangle (Lean Construction Institute 2017). UCSF developed a Construction Management (CM) at risk with design-build subcontractors and an incentives contract for the \$254 million Smith Cardiovascular Research Building. Then, it developed a design-build contract for the \$123 million Dolby Regeneration Medicine Building with "lean elements."

A critical component of Lean project delivery is the early involvement of key project stakeholders. Yet, UCSF being a large organization, has projects with many stakeholders. The difficulty that arises then is answering the questions: "Whom to involve in project delivery?" and "When to involve them?" UCSF has identified FM as a key project stakeholder.

\section{EVOLUTION OF FM PARTICIPATION IN DESIGN}

Figure 1 depicts the evolution of FM integration in project delivery at UCSF. On the upper half of the timeline, the shaded triangles of the Lean Project Delivery System (LPDS) schematic indicate when FM gets involved in project delivery. The triangles represent the five phases of the LPDS, from left to right: (1) project definition, (2) lean design, (3) lean supply, (4) lean assembly, and (5) use. On the lower half of the timeline, the evolution of FM integration is illustrated using five UCSF projects: (1) Genentech Hall, (2) Helen Diller Family Cancer Research Building, (3) Smith Cardiovascular Research Building, (4) Mission Hall, and (5) Block 33. The dates below the horizontal bars indicate the start and end of construction (the dates for the start of the project definition phase would have been a better indicator of UCSF's evolution with FM integration but these were not available at the time of this writing. They would have allowed readers to compare these dates with UCSF's changes in contracting practices and team selection processes.) 


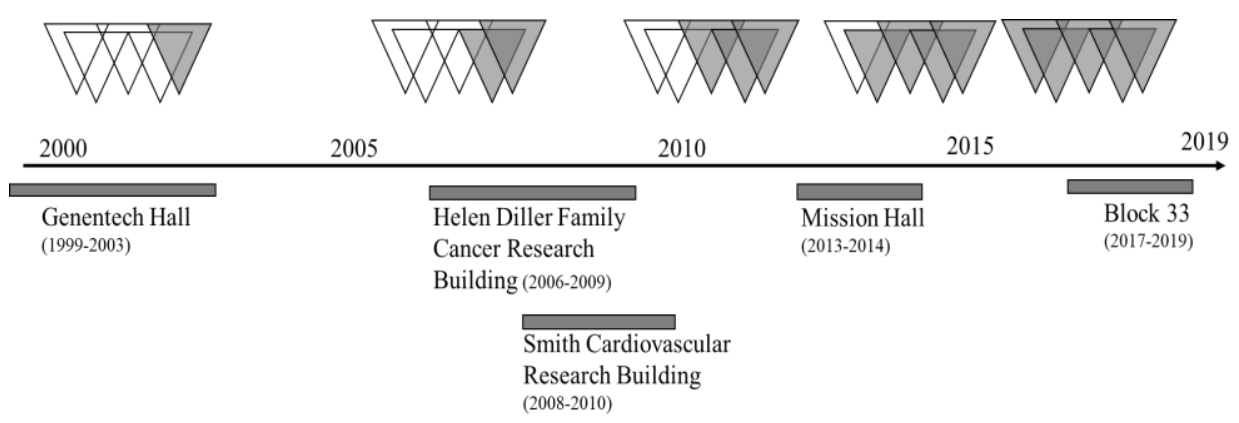

Figure 1: Evolution of FM Integration in Project Delivery at UCSF

Construction of Genentech Hall, UCSF's first building on Mission Bay, started in 1999 and was completed in 2003. The $\$ 161$ million five-story building houses programs in structural and chemical biology as well as molecular, cellular, and developmental biology. It also houses the Molecular Design Institute, Nikon Imaging Center and the Center for Advanced Technology.

At the time, UCSF had not started its Lean journey and FM was involved in the project use phase only. FM at UCSF gave the researcher examples of input that the project team could have requested from them but did not, due to a lack of active participation of FM in the design process. These include: needs in space (e.g., janitor closets, shops, storage rooms, etc.) or the type of water system to use. Concerning the latter, FM indicated they would have recommended the use of a Reverse Osmosis/Deionized water system as opposed to a deionized water system as delivered. Following this project, as UCSF started its Lean journey, FM started to be brought in earlier in project delivery.

Construction of the Helen Diller Family Cancer Research Building started in 2006. Occupancy started in 2009. This five-story building houses researchers investigating basic biological mechanisms causing cancer, including brain tumors, urologic oncology, pediatric oncology, cancer population sciences, and computational biology. Although UCSF had already initiated the development of new contracts for integrated project delivery teams, FM at UCSF reported that their involvement remained limited on this project. For example, they mentioned that the building was delivered before being fully commissioned, which FM would have recommended against had they been consulted.

Construction of the Smith Cardiovascular Research Building started in 2008 and was completed in 2010. The building houses nearly 500 research scientists and clinicians who work on the development of new treatments for cardiovascular diseases. This project is a landmark in UCSF's Lean journey: project team members met in the "big room" and were collocated in one large trailer. FM became more involved in the design phase and started to be recognized as important project stakeholders to consult when making design decisions.

Construction of Mission Hall started in 2013. The seven-story building was completed in September 2014. In terms of contractual relationships, UCSF had a designbuild contract with the architect and the GC, which the owner selected on best value. All project team members were involved early on the project, which supported the 
implementation of the Last PlannerTM System in the design phase. Furthermore, UCSF provided the competing design-build teams with the Technical Performance Criteria book version 1.0. In version 1.0, FM weighed in, but it was involved only after the project was awarded to discuss specific FM-related issues. In the first year of building occupancy, the energy profile of the building differed from customer expectations. In fact, FM was not familiar with the installed underfloor mechanical system. FM therefore had to learn how to operate it. Mission Hall was the first building at UCSF to be delivered with a two-year warranty.

Construction of the building on Block 33 started in 2017. The project will provide space split between two programs. The building will house academic and administrative office space (including desktop research, dry core and computational laboratories), and ophthalmology clinical space, called the "Center for Vision Neuroscience."

Contractually, the project is delivered under a Design-Build agreement which is UCSF's new Integrated Project Delivery (IPD)-like contract, binding the Architect to UCSF, and the GC to UCSF. The contract is qualified as "IPD-like," because it is not a multi-party agreement ("true" IPD contracts presumably are multi-party contracts). However, the use of multi-party contracts is legally impossible for UCSF due to its public status and the contracting regulations that apply to public entities.

For this project, UCSF created the Technical Performance Criteria book version 2.0 as part of its project definition process. This book documents UCSF's expectations about the building from a performance perspective. It is meant to capture what UCSF's project stakeholders value, and to translate what they value into design criteria. Unlike the Technical Performance Criteria book version 1.0, version 2.0 is the result of close collaboration between FM and a design consultant, and active engagement of relevant project stakeholders to unveil operational and physical criteria, understand space requirements, define room layouts that promote efficiency and well-being, and understand past failures and successes by visiting existing spaces and learning from precedents.

\section{LESSONS LEARNED}

UCSF sees value in FMs' active participation in the design of facilities. Beyond the reasons commonly mentioned in the literature (i.e., ensuring maintainability of buildings), FM's active participation in design allows them to understand the complexity of the programs housed by a facility, well before building commissioning. This understanding is critical at UCSF, since the organization operates many high-end facilities, or in other words, facilities housing sophisticated systems and/or equipment, which performance is critical to allow the organization to meet its business objectives (e.g., hospital, laboratory, power plant, etc.).

Complex programs in high-end facilities require that FMs make trade-offs, e.g., between their preference for simple and easy-to-maintain systems and programmatic requirements that can only be met with complex systems. 


\section{CONCLUSIONS}

While FMs may prefer systems that are simple, maintainable, reliable, cost effective, and that they are familiar with, the design of high-end facilities involves one-of-a-kind interdependent systems that require training and expertise to maintain. Thus, when FM is involved late in the design of high-end facilities, conflicts are likely to arise between FM's requirements and the developed design, causing design iteration (at best) or FM's dissatisfaction. Conversely, when involved early, FM can better understand the programmatic requirements of a project. This, in turn, helps them specify maintenance requirements that are compatible with programmatic requirements. While UCSF has benefited from engaging FM earlier in their projects, of note is that their experimentation and learning when and whom to best involve from FM in project delivery is still ongoing.

\section{ACKNOWLEDGMENTS}

Development of this paper was supported in part by members of the Project Production Systems Laboratory (P2SL) at UC Berkeley. Any opinions, findings, and conclusions or recommendations expressed in this material are those of the authors and do not necessarily reflect the views of members of P2SL.

\section{REFERENCES}

Alexander, K. (1994). “A Strategy for Facilities Management.” Facilities, 21(11), 269274.

Assaf, S., Al-Hammad, A.-M., and Al-Shihah, M. (1996). "Effects of Faulty Design and Construction on Building Maintenance.” J. Perf. Constr. Facilities, pp. 171-174.

Atkin, B. and Brooks, A. (2015). Total Facility Management. Chichester, UK: Wiley Blackwell, 390 pp.

Aune, M. and Bye, R. (2005). "Buildings that Learn - the Role of Building Operators." ECEEE Summer Study, Panel 2: Making Building More Energy Efficient, Mandelieu La Napoule, France, 30 May - 4 Jun., pp. 415-422.

Aune, M., Berker, T., and Bye, R. (2009). "The Missing Link which was Already there." Facilities, 27(1/2), pp. 44-55.

Bade, M. and Haas, C. (2015). "Using Lean Design and Construction to Get More from Capital Projects." Government Finance Review, Apr., pp. 39-44.

Barrett, P. and Baldry, D. (2003). Facilities Management: Towards Best Practice. $2^{\text {nd }}$ Ed., Oxford, UK: Blackwell Publication, 280 pp.

Bascoul, A. (2017). Managing Project Structural Complexity by Integrating Facility Management in Planning, Designing, and Execution of High-End Facility Upgrades. PhD Diss., Civil and Environmental Engrg., Univ. of California, Berkeley, 265 pp.

Bascoul, A., Tuholski, S., and Tommelein, I. (2017). "Use of DSM to Capture Unplanned Design Iterations on a Facility Plant Upgrade Project." $19^{\text {th }}$ Int'l. DSM Conf., Espoo, Finland, Sept. 11-13, 10 pp.

Becker, F. (1990). The Total Workplace. New York, NY: Van Nostrand Reinhold, 336 pp. 
Chanter, B. and Swallow, P. (1996). Building Maintenance Management. London: Blackwell Science, $332 \mathrm{pp}$.

Clayton, M.J., Johnson, R.E., and Song, Y. (1999). "Operations Documents: Addressing the Information Needs of Facility Managers." Durability Building Materials Components, 8(4), pp. 2441-2451.

Enoma, A. (2005) "The Role of Facilities Management at the Design Stage." $21^{\text {st }} A n$. ARCOM Conf., London, UK, Sept. 7-9, pp. 421-430.

Finch, E. (2010). "Florence Nightingale: Pioneer of Facility Management." W070, 18 CIB World Building Cong., São Paulo, Brazil, Sept. 13-15, 8 pp.

Grimshaw, B. (2007). "History is Bunk': Considerations on the Future of FM." Facilities, 25(11/12), pp. 411-417.

Hamilton, D.K. (2006). "Evidence-Based Design Supports Evidence-Based Medicine in the Intensive Care Unit." Intensive Care Unit Management J. (Belgium), 6(3), 31 pp.

Kalantari, S., Shepley, M.M., Rybkowski, Z.K., and Bryant, J. (2017). "Designing for Operational Efficiency: Facility Managers' Perspectives on How their Knowledge can be Better Incorporated during Design." Architectural Eng. and Design Manage., 22 pp.

Lean Construction Institute (2017). "Lean Articles." Lean Construction Institute. <https://www.leanconstruction.org/learning/lean-articles/> (Feb 10, 2018).

McAuley, B. (2016). Identification of Key Performance Tasks to Demonstrate the Benefit of Introducing the Facilities Manager at an Early Stage in the Building Information Modeling Process on Public Sector Projects in Ireland. PhD Diss., Dublin Institute of Technology, Dublin, Ireland.

Meng, X. (2013). "Involvement of Facilities Management Specialists in Building Design: United Kingdom Experience.” J. Performance Constr. Facilities, 27(5), pp. 500-507.

Mitropoulous, P. and Howell, G.A. (2002). "Renovation Projects: Design Process Problems and Improvement Mechanisms." J. Manage. Eng., 18(4), pp. 179-185.

Nelson, M.L. and Alexander, K. (2002). "The Emergence of Supply Chain Management as a Strategic Facilities Management Tool." Euro FM Research Symp. in Facilities Manage., University of Salford, Salford, UK.

Nightingale, F. (1857). Notes on Nursing: What It Is and What It Is Not. New York City, NY, USA: New York Appleton-Century, 139 pp.

Noor, M.N.M. and Pitt, M. (2009). "A Critical Review on Innovation in Facilities Management Service Delivery.” Facilities, 27(5/6), pp. 211-228.

Regterschot, J. (1990). "Facility Management in Changing Organizations." Int'l. Symp. on Property Maintenance Manage. and Modernization, Singapore, March, pp. 146-55.

Rybkowski, Z.K. (2009). The Application of Root Cause Analysis and Target Value Design to Evidence-Based Design in the Capital Planning of Healthcare Facilities. PhD Diss., Civil and Environmental Eng., University of California, Berkeley, 265 pp.

Shohet, I.M. and Lavy, S. (2004). "Healthcare Facilities Management: State of the Art Review." Facilities, 22(7/8), 210-220. 
Tay, L. and Ooi, J.T.L. (2001). "Facilities Management: A 'Jack of all Trades'?" Facilities, 19(10), 357-363.

Ulrich, R. (1984). "View through a Window may Influence Recovery from Surgery." Science, 224(4647), 420-421.

Varcoe, B. (2000). "Implications for Facilities Management of the Changing Business Climate." Facilities, 18(10/11/12), 383-91.

Waheed, Z. and Fernie, S. (2009). "Knowledge based Facilities Management." Facilities, $27(7 / 8), 258-266$. 